Manuelle Medizin 2020 · 58:344

https://doi.org/10.1007/s00337-02000745-8

(c) Springer Medizin Verlag $\mathrm{GmbH}$, ein Teil von Springer Nature 2020

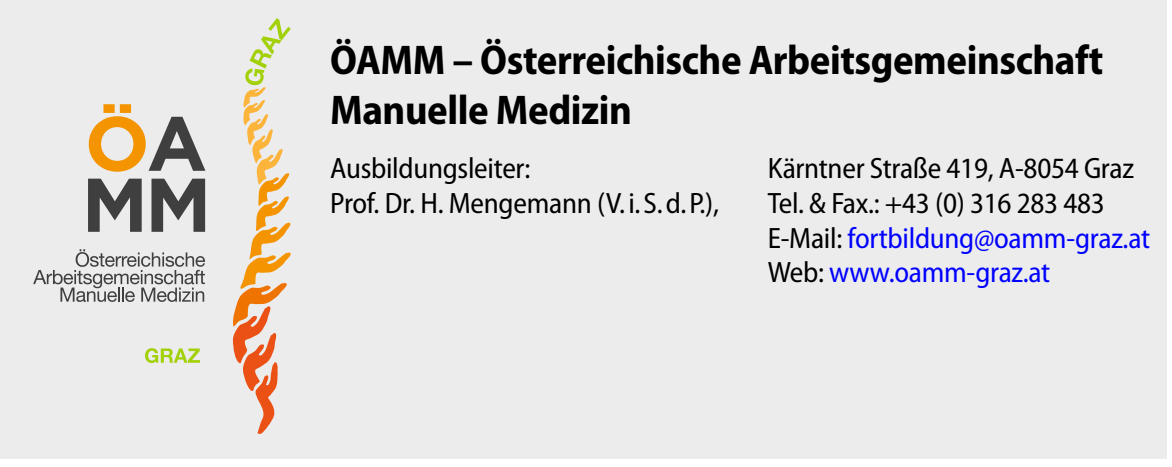

\section{Kurse 2020}

\section{Kurs 2}

12.12.-18.12.2020

Graz

KA2024

\section{Kurs 5}

28.11.-04.12.2020

Graz

KA2051

\section{Kurse 2021}

\section{Kurs 1}

16.01.-22.01.2021

25.01.-31.01.2021

20.03.-26.03.2021

17.06.-20.06. und

24.06.-27.06.2021

02.10.-08.10.2021

\section{Kurs 2}

01.05.-07.05.2021

05.06.-11.06.2021

07.10.-10.10. und

14.10.-17.10.2021

\section{Kurs 3}

06.02.-12.02.2021

21.02.-27.02.2021

25.02.-28.02. und

04.03.-07.03.2021

10.04.-16.04.2021

24.07.-30.07.2021

20.09.-26.09.2021

09.10.-15.10.2021

\section{Kurs 4}

17.04.-23.04.2021

04.09.-10.09.2021

13.11.-19.11.2021

\section{Kurs 5}

03.07.-09.07.2021

27.11.-03.12.2021
Graz

KA2141

Graz

KA2142

Graz KA2143

$\begin{array}{ll}\text { Graz } & \text { KA2111 } \\ \text { Wien } & \text { KA2112 } \\ \text { Graz } & \text { KA2113 } \\ & \\ \text { Bad Häring } & \text { KA2114 } \\ \text { Graz } & \text { KA2115 }\end{array}$

Graz KA2121

Wien KA2122

Bad Häring KA2123

Graz KA2131

Wien KA2132

Bad Häring KA2133

Graz KA2034

Graz KA2135

Wien KA2136

Graz KA2137

Graz KA2151

Graz KA2152

\section{Ausbildungsziel}

Das Erlernen von klinisch-manuellen Untersuchungstechniken am Stütz- und Bewegungssystem zur therapeutischen Beeinflussung von reversiblen Funktionsstörungen.

Die Fortbildung dient damit der Erweiterung des Angebotes der kurativen, rehabilitativen und präventiven Medizin.

\section{Zielgruppe}

ÄrztInnen für Allgemeinmedizin und FachärztInnen aller Sonderfächer.

\section{Teilnahmevoraussetzung}

Frühest möglicher Beginn der Fortbildung ist nach der Promotion.

\section{Weiterbildungsdauer/Stundenerfordernis}

Mindestens 1,5 Jahre, nach den Richtlinien der Österreichischen Ärztekammer sind für das ÖÄK Diplom Manuelle Medizin insgesamt 300 Fortbildungsstunden (100 Stunden Theorie, 200 Stunden Praxis und Demonstrationen) erforderlich.

\section{Wesentliche Inhalte}

Erkennen und Behandeln mit den Händen

Von der Arbeitshypothese zur Diagnose

Prävention

Rezidivprophylaxe

Terminänderungen/Absagen vorbehalten.

Wir weisen darauf hin, dass für die Kursteilnehmer der ÖAMM die Kurszeiten und Anwesenheitspflicht bindend sind!

Die Bestätigung der Fortbildungspunkte durch die österreichische Ärztekammer ist an die Erfüllung der Kursrichtlinien gebunden.

Verbindliche Anmeldungen und Auskünfte im Sekretariat der ÖAMM E-Mail: fortbildung@oamm-graz.at

Internet: www.oamm-graz.at

Adresse: Kärntner Straße 419, $8054 \mathrm{Graz}$

Tel. \& Fax: +43 (0) 316-283 483 